\title{
The method of forming solutions for non-critical activities in the preparation and optimization of the construction complex organizations' annual program
}

\author{
Pavel Oleinik ${ }^{1}$ and Alexey Yurgaytis ${ }^{1, *}$ \\ ${ }^{1}$ Moscow State University of Civil Engineering, Yaroslavskoe shosse, 26, Moscow, 129337, Russia
}

\begin{abstract}
The article considers the possibility of identifying a group of companion activities in the annual construction program of organizations that does not lie on the critical path of the network model and which can be performed at the expense of the resource of subcontractors. The authors, using statistical methods, analyzed the experience of planning the production activities of a number of Russian and foreign construction companies on the territory of the Russian Federation to evaluate the application of the proposed optimization instrument without damage to the production process and without the risk of losing managerial control over the construction sites.
\end{abstract}

\section{Introduction}

The production planning of construction activities is a multi-criteria complex of sequence solved tasks [1]. In the framework of this scientific work, annual (current) planning is considered as a definite fundamental basis, which has a significant influence on the decisionmaking of other planning levels of construction production (Fig. 1). At the stage of annual (current) planning, the production structures face the principal task of linking several factors: "The duration of construction and installation works at the objects according to the contracts (time factor) - the location of the objects (spatial factor) - the distribution of construction organization's capacity (resource factor)" (Fig. 2). In terms of the latter, a very common practice scheme is the attraction of subcontractors with their own resources (capacity) to perform a certain proportion of the total volume of construction and installation work for the main production program. In this case, the specified amount flows into the production program of the subcontractor and does not require fundamental actions to plan the organization's own resource in terms of such activities. Along with preliminary calculations, this is especially important in the case of optimization of an already compiled and approved production program in the context of adding additional objects during the annual accounting period (the annual program) and other destabilizing factors causing significant fluctuations in the constant resource parameter. The authors consider the possibility of scientific justification for the maximum amount of work allowed for the transfer to the subcontractors'

*Corresponding author: aljurgaitis@gmail.com 
zone of responsibility without damage to the production process and without the risk of losing the management control of the General Contractor over the construction sites. This approach is seldom used in the formation of schedules and production program [2-7].

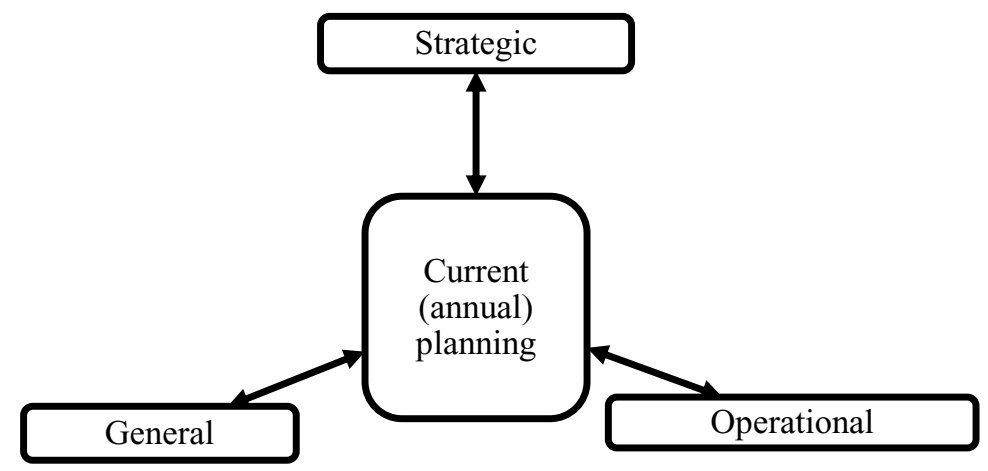

Fig. 1. Interrelation of planning industrial activity levels.
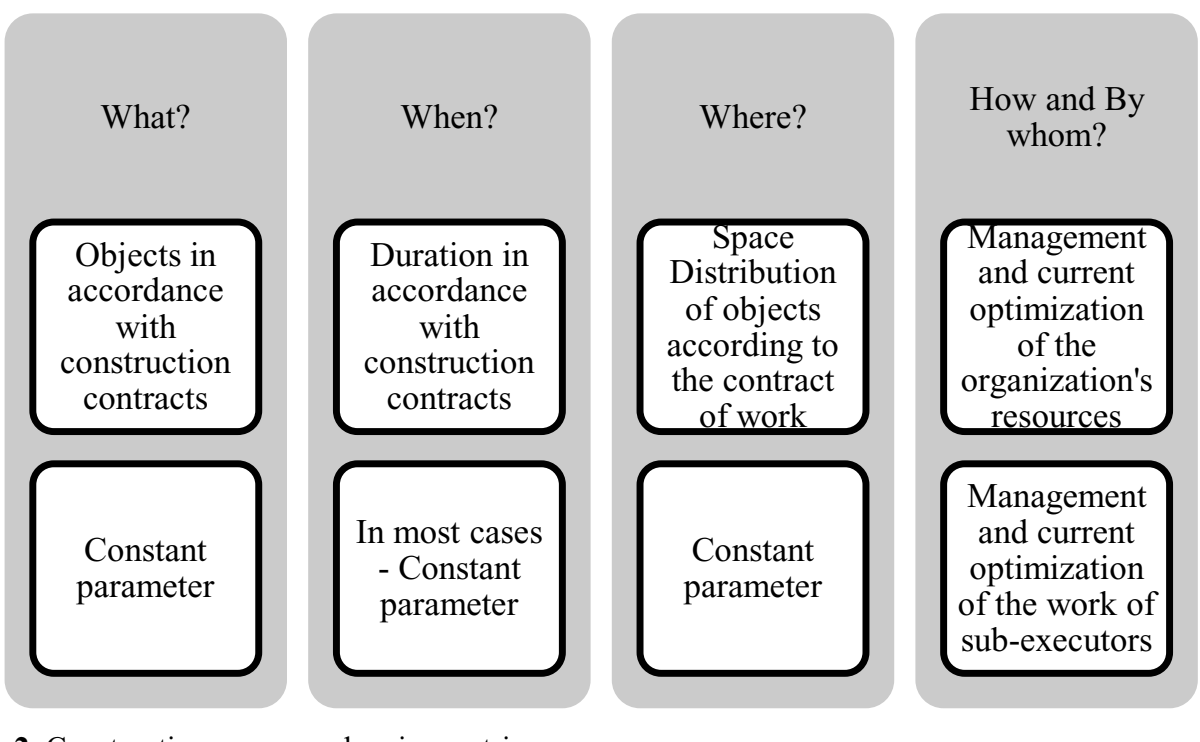

Fig. 2. Construction program planning matrix.

Initially, it is necessary to determine the essential area of responsibility for the General contractor organization - despite the practice of maximizing involvement of outside subcontractors under subcontract agreements (especially for organizations characterized by low capacity and acting as a general contractor, in fact, nominally), in the classical understanding, the general contractor to ensure the management of its annual production program should produce a significant amount of work by itself, including the critical activities of the main production stream (the assembly of monolithic structures, the erection of carcass structures, etc.). Thus, in a statistical analysis of the experience of overflowing the volume of construction and installation work to subcontractors, took part amount of contractors that represented several groups, characterized by different levels of initial capacity (large, medium and small). Organizations those are so powerless that they can't even produce work on the critical path by itself and by their own capacity, and also can't provide the leading production stream with the resource. For this reason, the following boundary 
condition is established: the General contractor has to perform at least $50 \%$ of the total work volume by its own capacity, using its own resource. That'll be a general contractor's guarantor of management stability on construction sites.

\section{Materials and methods}

Let us consider the entire range of possible construction and installation works at industrial and civil construction sites (Fig. 3). In this vein, within the limits of, for example, one object, it is possible to divide all the specified construction and installation activities into two principal groups by the criterion of the admissibility of transfer to the subcontractors' department: work of the main stream (critical) and so-called accompanying works (companions; noncritical) (Fig. 4). Thus, special types of construction activities often turn into the "companion" status and they are transferred to subcontract, the same can be observed with a number of general non-critical works, if the general contractor organization does not specialize in them.

At this stage, for the obviously relevant mechanism of optimizing the plan and resource provision by transferring a number of works to the sub-contractor, it is important to establish an allowable fraction of the scope of such activity and a criterion for the applicability of the method. An array of data from the parent population of the construction organizations being analyzed (25 companies) was formed on the basis of information from open source sources (statistical data of periodical printed and electronic editions of the building profile, published annual production activities reports, communication of authors with official representatives of the said organizations, etc.) and also by analyzing of the budget documents and organizations' schedules. As mentioned above, provided organizations had a certain level of resources (capacity) to perform by their own forces at least $50 \%$ of the total volume of activities of the production program. At the same time, this minimum amount of work volume has to contain activities performed by the leading streams. These conditions, which limit the scope of the total number of contractors, make it possible to exclude from parent population a significant number of construction companies acting on construction sites as the General Contractor, but at the same time transferring all production management to subcontractors. 


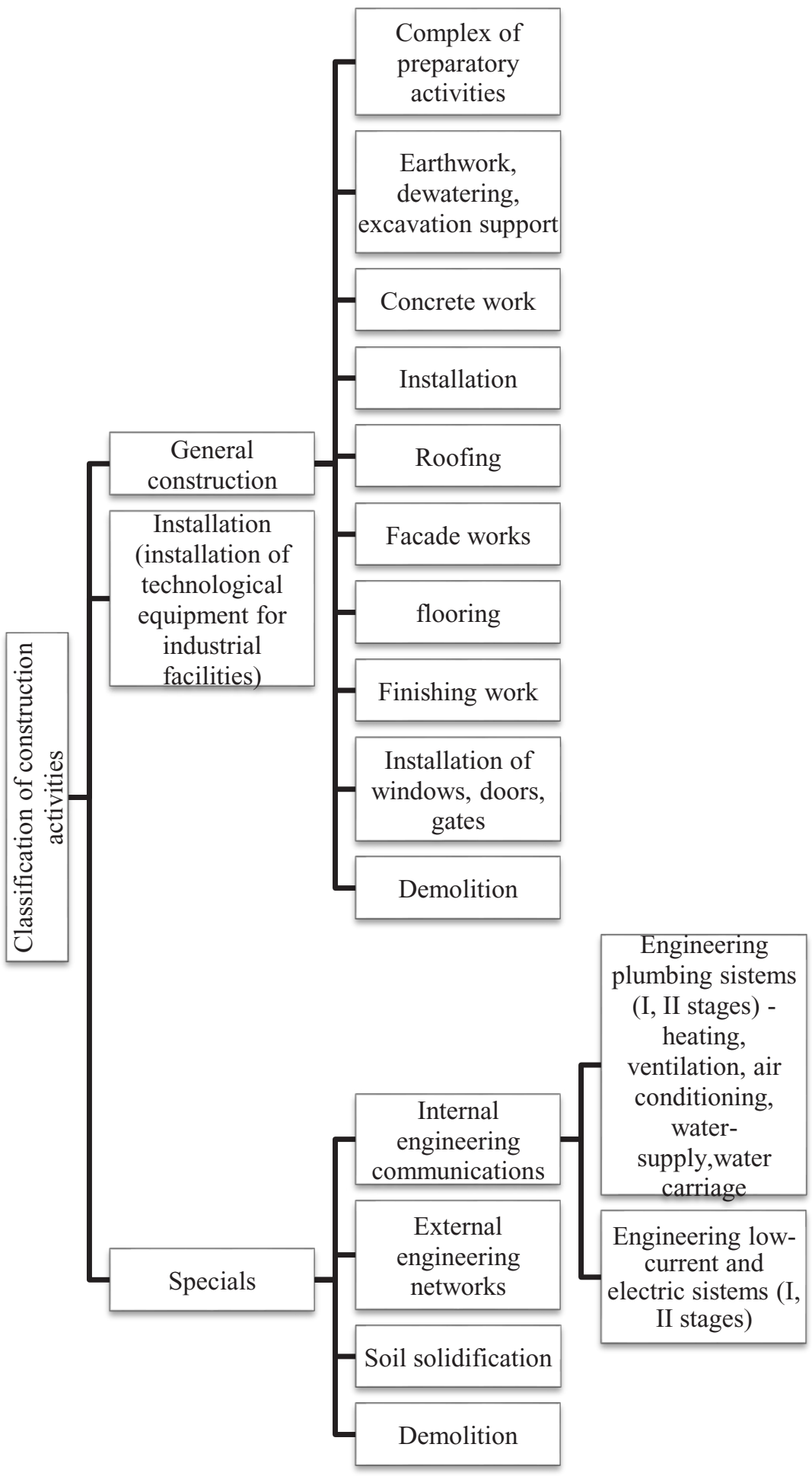

Fig. 3. The scheme of linking the types of construction and installation works on the site. 


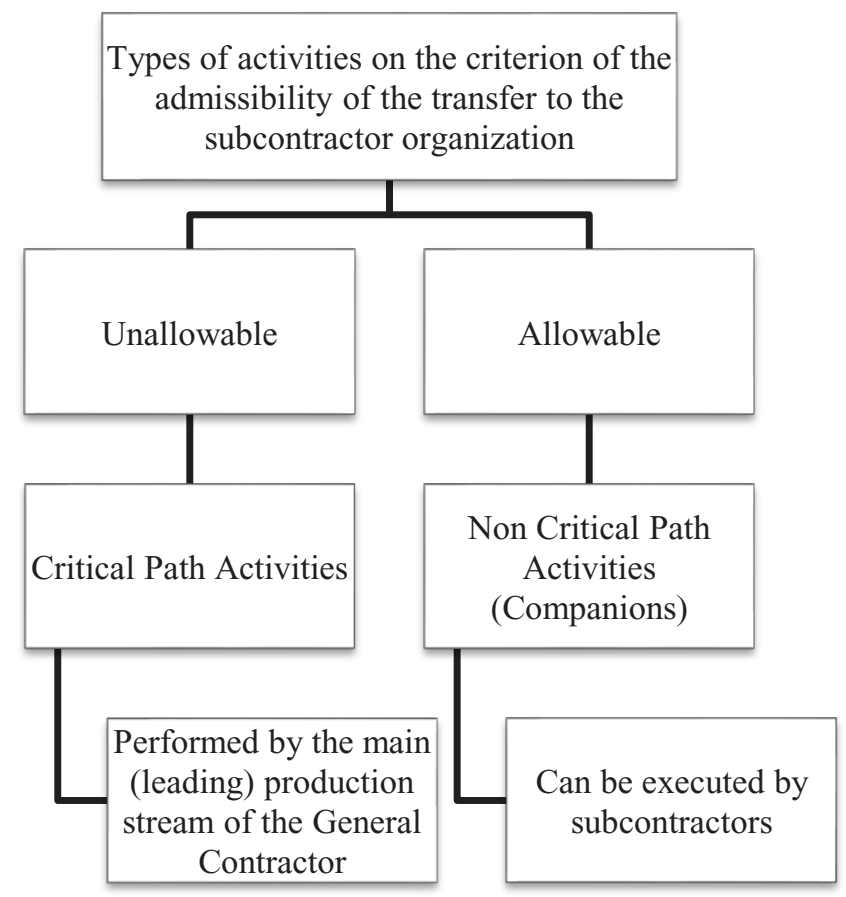

Fig. 4. Scheme linking the types of construction and installation work on the admissibility of the transfer of the subcontractor organization.

The authors analyzed the annual activity of 25 construction organizations on the following indicators:

1. specialization of the construction organization (construction of residential, commercial, industrial buildings, etc.);

2. turnover of financial resources (revenue) by specialization, million rubles for the fiscal year with VAT;

3. The volume of the portfolio of sold objects in the primary market (finished construction products) per year, billion rubles, including VAT, in monetary terms according to the production program;

4. The volume of the portfolio of consummated objects in the primary market (finished construction products) per year, million $\mathrm{m}^{2}$ - in physical terms according to the production program;

5. determination of the leading flow;

6. averaged share of subcontract works, $\%$.

\section{Results}

As a result of the statistical analysis it has been established that the main layer of general contracting organizations carrying out their primary housing stock construction activities on the territory of the Russian Federation can be divided into three main principled groups by the criterion of the resource availability, material and technical bases for the implementation of annual production program activities. Thus, the largest representatives have sufficient means of mechanization and labor (line personnel, engineering staff) on their own balance sheet or in the leasing regime to carry out the entire range of work on their construction projects, including special types such as installation of sanitary, electro technical systems and 
a number of others (Fig. 5). This group of representatives forms the first class of the optimization task, in which the competent redistribution of the own resource will allow to form a calendar plan and a correct production program. Accordingly, such organizations have the largest amount of work on the production program. Decisions of the second and third classes of tasks, covering the majority of construction companies, will allow ensuring the flow of the established scope of work under the production management of subcontractors without critical consequences. This includes smaller organizations with smaller object portfolio.
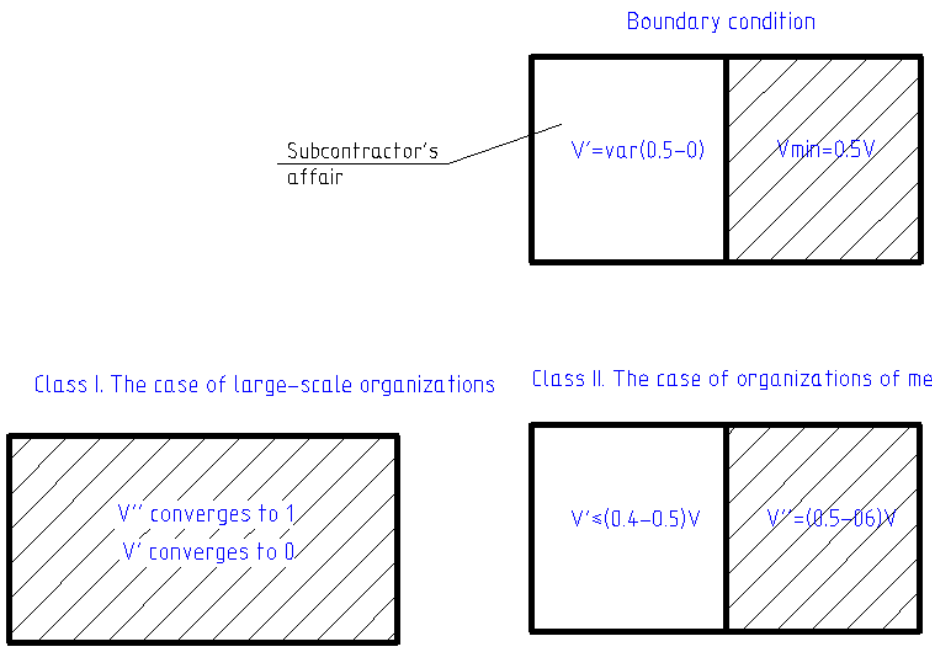

Class III. The case of small power organizations

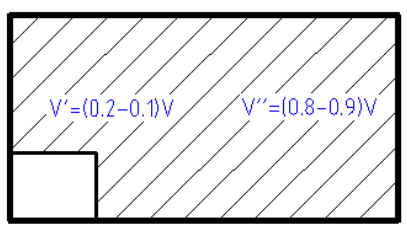

Fig. 5. The main classes of tasks in terms of the source capacity.

$$
\begin{gathered}
V^{\prime}=\operatorname{var}(0.0 \div 0.5) V \\
V^{\prime}=f(V) \\
V^{\prime \prime} \geq V_{\text {min }} \geq 0.5 \mathrm{~V}
\end{gathered}
$$

$V$ - total activities volume of the annual production program;

$V^{\prime}$ - share of the total amount of work of the production program, implemented by subcontractors;

$V_{\text {min }}$ - the established minimum (control) share of the total amount of production program activities that provides production management functions at construction sites and is realized directly with the involvement of the general contractor's resource (includes the scope of work performed by the leading construction flows);

$V^{\prime \prime}$ - share of the total amount of production program activities, implemented directly with the involvement of the general contractor's resource (includes the scope of work performed by the leading flows). 
The total effort performed under construction contracts of the production program (V) will be:

$$
V=V^{\prime \prime}+V^{\prime}
$$

The optimization solution is formed on the basis of the solutions of two successive tasks:

1. Definition of the group (I-III group) of the construction organization by the criterion of the initially available resource (capacity).

2. Determination of the maximum proportion of the effort to be performed for the transfer to a subcontractor without loss of the management instrument over the main, critical types of work and construction sites in general.

The sample of construction organizations from the parent population was analyzed in terms of the erection of residential buildings, and graphically dependence (2) is described by a set of exponential functions (a family of curves) for construction organizations of each type. For large construction organizations, for example, the analytical method for determining the maximum allowable effort transferred to production control by subcontractors is determined by solving Equation 5 .

$$
V^{\prime}=0.7013 e^{-0.04 V^{\prime \prime}}
$$

\section{Conclusion}

Forming an effective methodology for planning and optimizing the annual production program is an extremely topical issue. It is obvious, however, that the General contractor should link the work not only within this own program, but also between subcontractors. With regard to the considered optimization method, we can say that by developing a similar methodology for different types of organizations and specializations of the construction profile, it is possible to identify functional dependencies and to calculate analytically the amount of work that is permissible for transfer to a subcontractor without risks for control over construction sites using mathematical tools and statistical methods. And vice versa - the necessary minimum volume of construction and installation works, necessary and sufficient for the General Contractor to ensure the management function and resource support of the leading stream.

\section{References}

1. B.F. Shirshikov, Organization, planning and management of construction (ASV, Moscow, 2016)

2. P.P. Oleinik, Organization of construction production (ASV, Moscow, 2010)

3. M. Said Easa, ASCE. Journal of Con-struction Engineering and Management (1989)

4. S. Farzad Moosavi, Osama Mosehli, Review of Detailed Schedules in Building Construction, ASCE. Journal of Legal Affairs and Dispute Resolution in Engineering and Construction (2014)

5. Y. Tang, R. Liu, Q. Sun Two-Stage, ASCE. Journal of Construction Engineering and Management (2014)

6. M.Cheng, D. Prayogo, Duc-Hoc, ASCE. Journal of Computing in Civil Engineering (2016)

7. S. Mubarak, Construction Project Scheduling and Control (John Wiley \& Sons, Canada, 2010) 